\title{
An unusual case of giant coronary sinus causing left ventricular inflow obstruction
}

Deepak Gowda, DNB, C. H. Praveen, MBBS, Aaditya Sirohi, MD, and Neelam Desai, MCh, DNB, Andhra

Pradesh, India

From the Department of Cardio Thoracic and Vascular Surgery, Sri Sathya Sai Institute of Higher Medical Sciences, Prasanthigram, Andhra Pradesh, India.

Disclosures: Authors have nothing to disclose with regard to commercial support.

Received for publication July 12, 2016; revisions received Aug 10, 2016; accepted for publication Aug 25, 2016; available ahead of print Sept 29, 2016.

Address for reprints: Deepak Gowda, DNB, Department of Cardio Thoracic and Vascular Surgery, Sri Sathya Sai Institute of Higher Medical Sciences, Prasanthigram, Room No. 251, Puttaparthy, Anantapur District, 515134 Andhra Pradesh, India (E-mail: drdeepakgowda@gmail.com).

J Thorac Cardiovasc Surg 2017; 153:e27-9

$0022-5223 / \$ 36.00$

Copyright (C) 2016 by The American Association for Thoracic Surgery

http://dx.doi.org/10.1016/j.jtcvs.2016.08.059

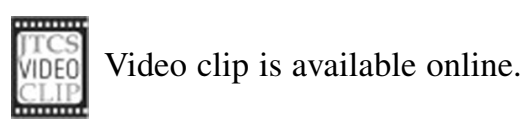

The left-sided superior vena cava (LSVC) is thought to be a remnant of the embryologic left anterior cardinal vein. Its prevalence has been reported to be approximately $3 \%$ in isolation and up to $2.8 \%$ to $4.3 \%$ in the presence of congenital heart disease. ${ }^{1}$ Patients with persistent LSVC and dilated coronary sinus seem to have a higher incidence of associated left-sided obstructive lesions. ${ }^{2}$ We describe successful relief of left ventricular inflow obstruction (LVIO)

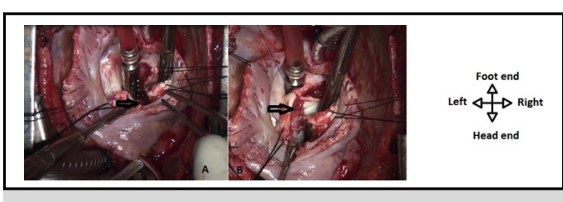

Cut back of coronary sinus $(A)$ and partial plication $(B)$

Central Message

An unusual case of left ventricular inflow obstruction caused by left superior vena cava draining to the coronary sinus, supramitral ring, and absent right superior vena cava and its successful management.

See Editorial Commentary page e31.

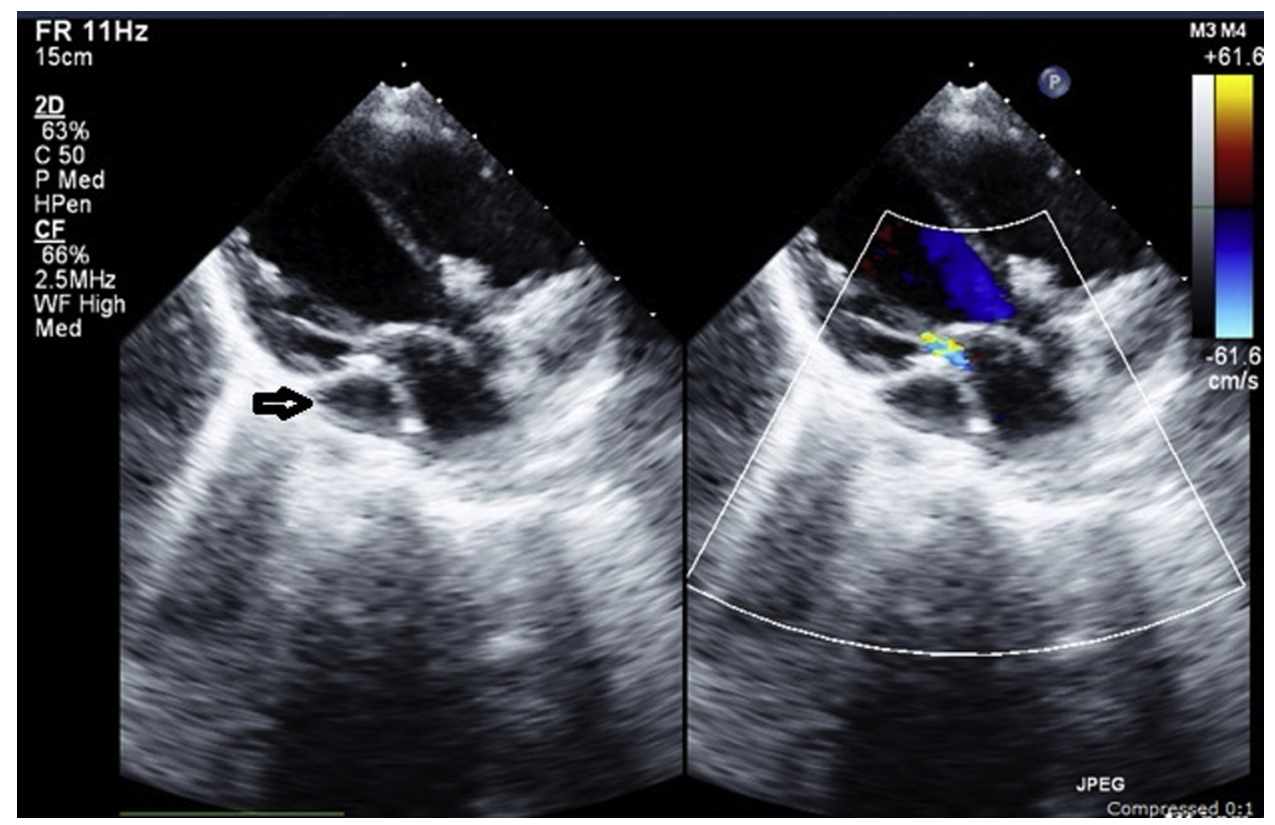

FIGURE 1. Parasternal long-axis view showing a hugely dilated coronary sinus. 


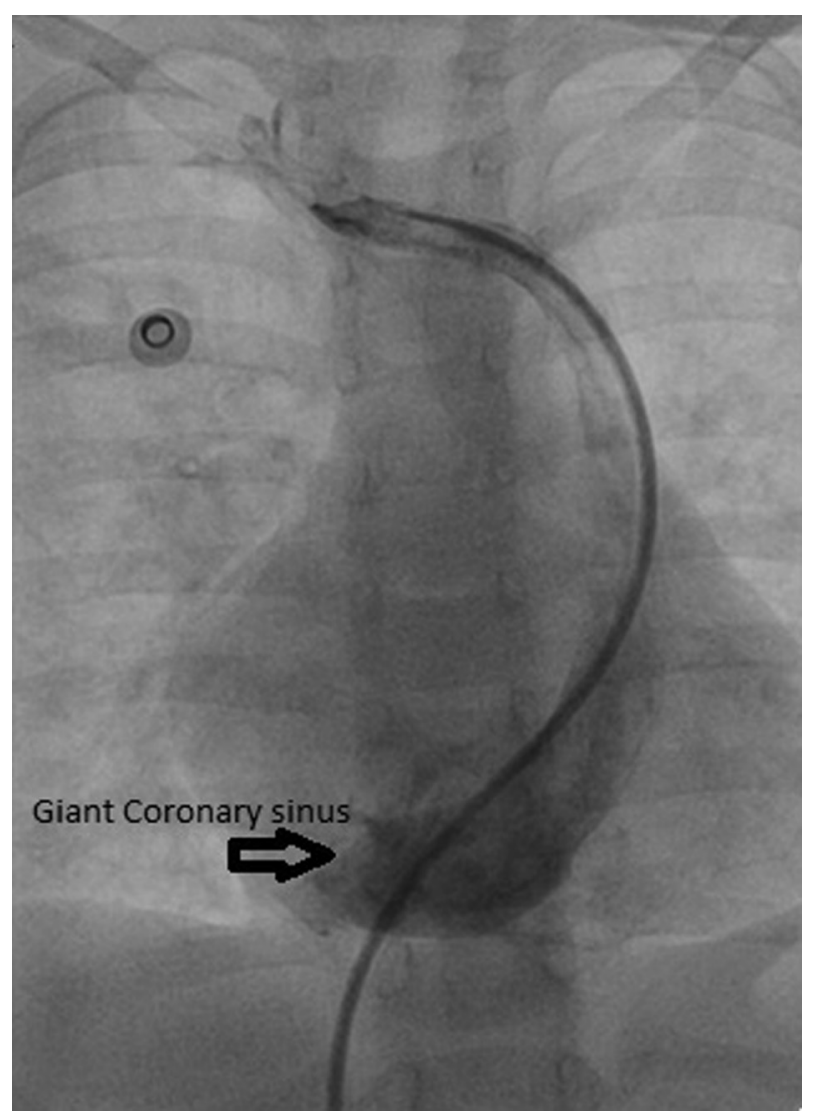

FIGURE 2. Catheterization study showing absent right superior vena cava. Catheter is seen in the left superior vena cava, which is draining into dilated coronary sinus.

be confirmed in a parasternal long-axis view and a modified apical four-chamber view with posterior tilt (Figure 1).

\section{CASE PRESENTATION}

A male child aged 3 years and 9 months was admitted with the complaint of recurrent respiratory tract infection. Transthoracic echocardiography revealed a supramitral ring with a mitral valve gradient of $19 / 7 \mathrm{~mm} \mathrm{Hg}$, a tiny perimembranous ventricular septal defect (PM VSD) restricted by a septal leaflet of the tricuspid valve, and moderate

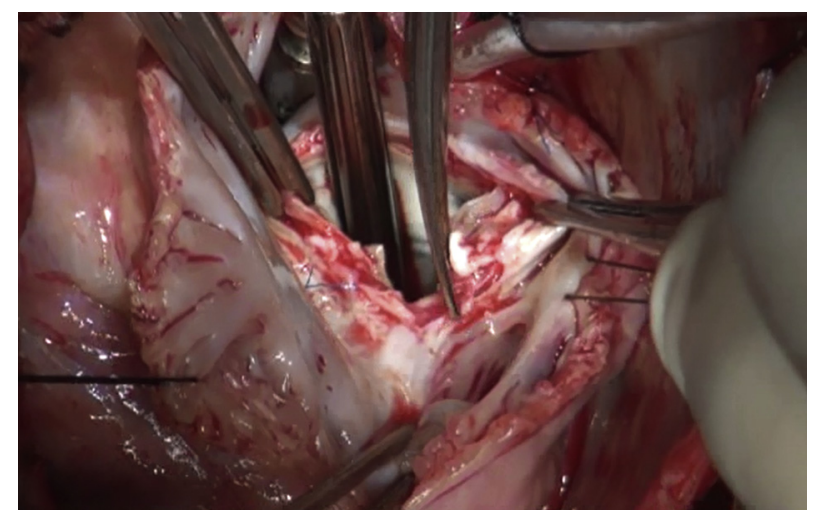

VIDEO 1. Video demonstrating the giant coronary sinus causing the LVIO and the reduction plasty of the coronary sinus in process to relieve the LVIO. Video available at: http://www.jtcvsonline.org/article/S00225223(16)31096-0/addons.

tricuspid regurgitation with severe pulmonary arterial hypertension. The patient underwent cardiac catheterization, which revealed a mean gradient of $16 \mathrm{~mm} \mathrm{Hg}$ across the left atrium and the left ventricle, an absent right superior vena cava, with persistent large draining of the left superior vena cava to the coronary sinus (Figure 2), and an operable small PM VSD.

The supramitral ring was excised intraoperatively and the VSD was closed with a Dacron patch. After cardiopulmonary bypass, transesophageal echocardiography showed no residual VSD and no significant gradient across the mitral valve and trivial mitral regurgitation and no tricuspid regurgitation.

The patient gradually developed noncoapting tricuspid valve leaflets with severe tricuspid regurgitation, ascites, hepatomegaly, and moderate mitral regurgitation, and a catheterization study revealed a mean gradient of $10 \mathrm{~mm}$ $\mathrm{Hg}$ across the left ventricular inflow tract. Because of the child's deteriorating clinical condition, we decided to repair the tricuspid valve. During the surgery, an abnormally giant coronary sinus was present and thought to be the cause of the LVIO. Hegar dilators of appropriate size were passed through the mitral valve, and we then made the decision

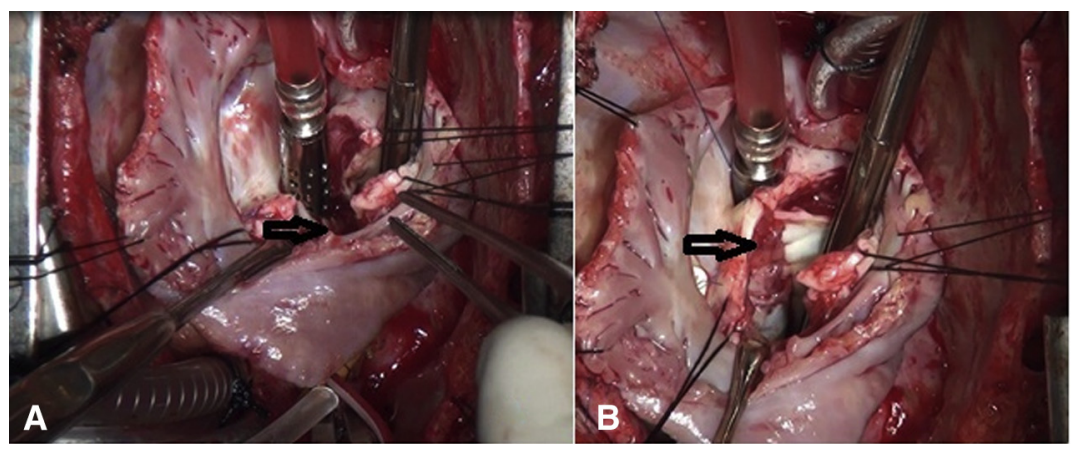

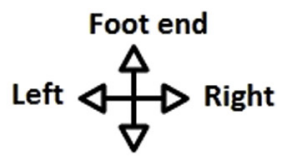

Head end

FIGURE 3. Cut back of the coronary sinus (sucker inside the coronary sinus) (A) and plication with the sucker inside the coronary sinus (B). 


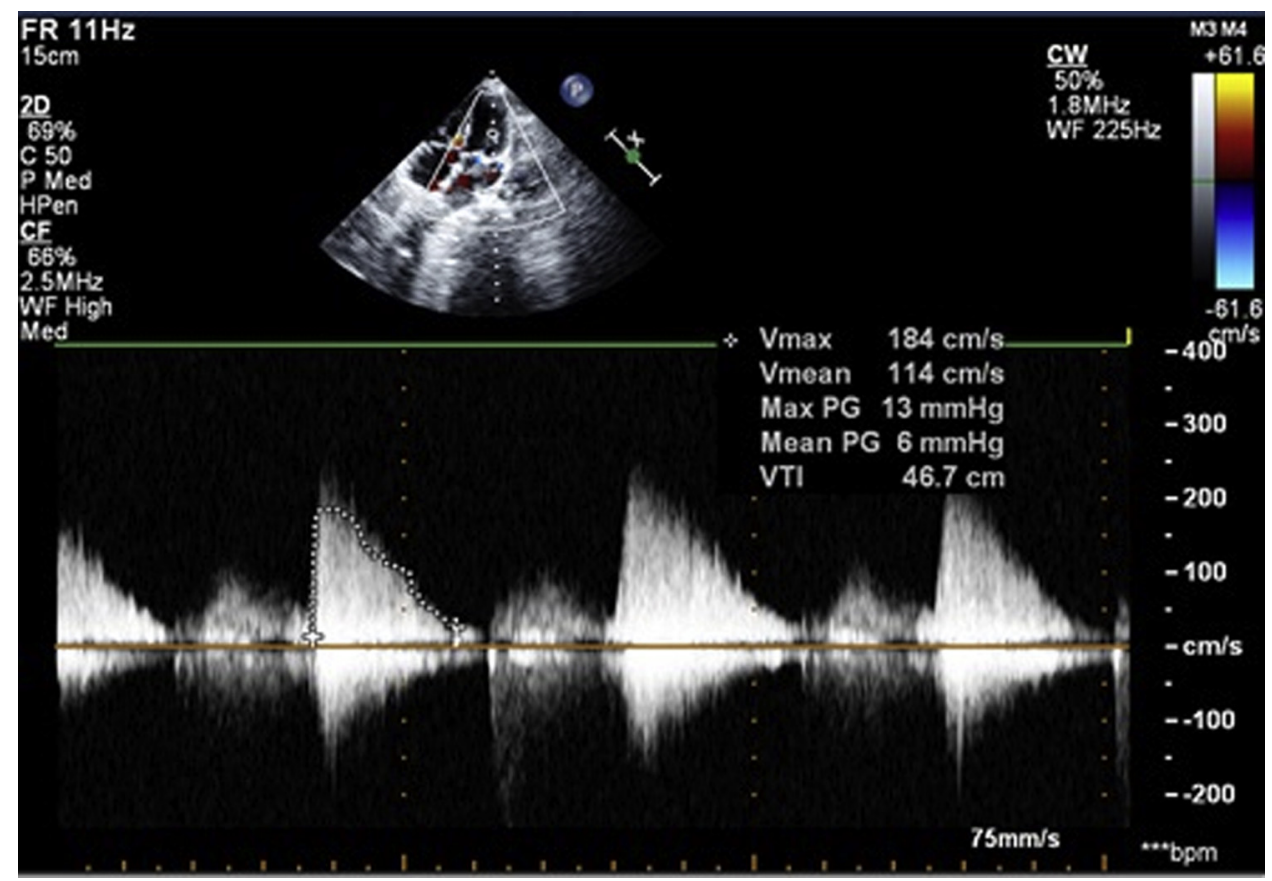

FIGURE 4. Postcoronary sinus plication: parasternal long-axis view showing the mitral valve gradient.

on the amount of plication of the coronary sinus needed. Partial plication of the dilated coronary sinus was done through the right atrium (Figure 3 ). The coronary sinus was cut back, as shown in Figure 3, and the cut ends were then plicated, thus reducing the orifice of the coronary sinus, which was the cause of the LVIO (Video 1). The interatrial septum was closed with a Dacron patch, and the tricuspid valve was repaired using De Vega's annuloplasty. The patient's clinical condition improved after repair, with echocardiography showing regression of tricuspid regurgitation and mitral regurgitation and no significant gradient across the left ventricular inflow tract (Figure 4).

\section{DISCUSSION}

Echocardiography may not distinguish a supramitral ring or a giant coronary sinus as the cause of LVIO. Recent literature suggests that persistent LSVC may exert a mechanical effect on the developing left side of the heart and lead to a higher incidence of associated left heart obstructive lesions. Autopsy findings have demonstrated a higher prevalence of such lesions in patients with LSVC. ${ }^{3}$ Agnoletti and colleagues ${ }^{2}$ reviewed catheterization findings and concluded that left-sided obstruction was more prevalent in patients with than without LSVC $(39.6 \%$ vs $7.8 \%$, respectively), whereas the prevalence of right-sided obstructive lesions was similar. A statistically strong positive correlation was present between adjusted coronary sinus measurements adjusted for body surface area and mitral mean gradient. ${ }^{4}$

\section{CONCLUSIONS}

A giant coronary sinus causing left ventricular inflow obstruction is a rare congenital anomaly. The concomitant presence of a supramitral ring should alert the surgeon to the need to repair the dilated coronary sinus, especially when the left superior vena cava is the sole means of systemic drainage.

\section{CONSENT}

Written informed consent was obtained from the child's parents for publication of this case report and any accompanying images.

\section{References}

1. Lucas RV, Krabill K. Abnormal systemic venous connections. In Emmanouilides GC, Riemenschneider TA, Allen HD, Gutgesell HP, eds. Moss \& Adams: Heart Disease in Infants, Children, and Adolescents. Baltimore: Williams \& Wilkins; 1995:875.

2. Agnoletti G, Annecchino F, Preda L, Borghi A. Persistence of the left superior caval vein: can it potentiate obstructive lesions of the left ventricle? Cardiol Young. 1999;9:285-90.

3. Macedo AJ, Oosthoek PW, Wenink ACG, Bartelings MM. Does persistent left superior vena cava to coronary sinus influence the growth of the left heart in the fetus? Cardiol Young. 1996;6:101.

4. Kizilkan N, Davutoglu V, Erbagci H, Karagoz A, Akcay M, Sari I, et al. Coronary sinus dilatation. Saudi Med J. 2010;31:153-7. 